PAPER

\title{
Neurodevelopmental treatment after stroke: a comparative study
}

\author{
T B Hafsteinsdóttir, A Algra, L J Kappelle, M H F Grypdonck, on behalf of the Dutch NDT Study \\ Group*
}

See end of article for authors' affiliations

Correspondence to:

Dr Ale Algra, Department

of Neurology and Julius

Centre, University Medical

Centre Utrecht, STR 6.131,

PO Box $85500,3508 \mathrm{GA}$

Utrecht, Netherlands;

A.Algra@umcutrecht.n

Received 29 March 2004

In revised form

22 September 2004

Accepted

24 September 2004

*Members of the Study

Group are listed at the end

of the paper
Background: Neurodevelopmental treatment (NDT) is a rehabilitation approach increasingly used in the care of stroke patients, although no evidence has been provided for its efficacy.

Objective: To investigate the effects of NDT on the functional status and quality of life (QoL) of patients with stroke during one year after stroke onset.

Methods: 324 consecutive patients with stroke from 12 Dutch hospitals were included in a prospective, non-randomised, parallel group study. In the experimental group $(n=223)$, nurses and physiotherapists from six neurological wards used the NDT approach, while conventional treatment was used in six control wards $(n=101)$. Functional status was assessed by the Barthel index. Primary outcome was "poor outcome", defined as Barthel index $<12$ or death after one year. QoL was assessed with the 30 item version of the sickness impact profile (SA-SIP30) and the visual analogue scale.

Results: At 12 months, 59 patients (27\%) in the NDT group and $24(24 \%)$ in the non-NDT group had poor outcome (corresponding adjusted odds ratio $=1.7$ (95\% confidence interval, 0.8 to 3.5)). At discharge the adjusted odds ratio was $0.8(0.4$ to 1.5$)$ and after six months it was $1.6(0.8$ to 3.2). Adjusted mean differences in the two QoL measures showed no significant differences between the study groups at six or 12 months after stroke onset.

Conclusions: The NDT approach was not found effective in the care of stroke patients in the hospital setting. Health care professionals need to reconsider the use of this approach.
$\mathrm{N}$ eurodevelopmental treatment $(\mathrm{NDT})^{1}$ is a rehabilitation approach widely applied by nurses and physiotherapists caring for stroke patients. ${ }^{23}$ It is based on neuroplasticity theories. ${ }^{45}$ According to the NDT approach, stimulation of the affected side improves rehabilitation results. ${ }^{1}$ Nurses promote maximal bilateral function as they encourage the patient to relearn lost automatic movements. They use stimulating and inhibiting exercises to normalise muscle tone, and apply balance exercises to help the patient relearn normal postural balancing. ${ }^{16}$ The NDT approach has been criticised for being costly and time consuming, as nurses and other health care professionals need to follow extensive training in how to apply the complex NDT techniques when assisting patients with mobility and activities of daily living. NDT has also been criticised for being based on outdated theories, with techniques that increase patient passivity and show poor carryover gains into real life situations.?

There is a paucity of efficacy studies supporting the NDT approach. ${ }^{2}$ Of the eight studies conducted, ${ }^{8-15}$ only one showed positive effects on the patients' functional status on discharge from hospital. ${ }^{14}$ Other studies showed no beneficial effects $^{8-101213}$ or even a negative impact (for example, increased length of stay). ${ }^{11}{ }^{15}$ However, these studies were hampered by small sample size, execution at a single site, and the lack of baseline evaluation. None of the studies provided data on an intervention check, and the inclusion criteria did not focus on patients who could benefit most from rehabilitation nursing interventions. ${ }^{2}$ Moreover, not all studies employed outcome criteria based on the International Classification of Functioning, Disability and Health (ICF). ${ }^{16}$ Finally, a recent Cochrane review concluded that there was insufficient evidence that any particular physiotherapy treatment approach was more effective than any other in promoting recovery of postural control or lower limb function after stroke. ${ }^{17}$
In the current study we investigated the effects of the NDT approach in the treatment of hospital inpatients with stroke on the functional outcome and quality of life (QoL) one year after the stroke.

\section{METHODS}

\section{Study design}

Two groups of stroke patients were compared using a prospective, non-randomised, parallel group design. In the experimental group, nurses and physiotherapists on six neurological wards used the NDT approach, while in the control group the nurses and physiotherapists on six other neurological wards did not use the approach. Of the 12 hospitals participating in the study, three (two in the NDT group) were university hospitals and nine were general hospitals.

\section{Patients}

Patients were included if they had a clinical diagnosis of stroke, based on the World Health Organisation (WHO) definition. ${ }^{18}$ Additional inclusion criteria were: Glasgow coma scale score at least 14 (or an eye-motor score of 9 in aphasic patients) on admission ${ }^{19}$; at least moderate handicap on admission (Rankin scale $>3$ ), ${ }^{20}$ but not before stroke onset (Rankin scale $<3$ ); no severe dementia, defined as a minimental state examination (MMSE) score of 7 or higher ${ }^{21}$; informed consent; and Dutch speaking.

Patients read and signed an institutional review board/ ethics committee approved informed consent before inclusion in the study. Eligible patients were screened for inclusion between day 3 and day 5 after stroke onset. Baseline variables

Abbreviations: CES-D, Center of Epidemiological Studies depression scale; MMSE, mini-mental state examination; NDT, neurodevelopmental treatment; QoL, quality of life; SA-SIP30, stroke adapted 30 item version of the sickness impact profile 
Table 1 Baseline characteristics of patients

\begin{tabular}{|c|c|c|}
\hline Variable & $\begin{array}{l}\text { NDT treatment } \\
(n=223)\end{array}$ & $\begin{array}{l}\text { Non-NDT } \\
\text { treatment } \\
(n=101)\end{array}$ \\
\hline Stroke onset to admission (d) & $0.32(1.1)$ & $0.59(2.4)$ \\
\hline \multicolumn{3}{|l|}{ Demographic characteristics } \\
\hline Female (\%) & $101(45 \%)$ & $50(50 \%)$ \\
\hline Age (years) & $68(13)$ & 72 (11) \\
\hline Living alone & $75(34 \%)$ & $53(53 \%)$ \\
\hline \multicolumn{3}{|l|}{ Education } \\
\hline$\leqslant 6$ years & $84(38 \%)$ & $33(33 \%)$ \\
\hline $6-12$ years & $102(46 \%)$ & $55(55 \%)$ \\
\hline$>12$ years & $36(16 \%)$ & $12(16 \%)$ \\
\hline \multicolumn{3}{|l|}{ History } \\
\hline Stroke & $47(21 \%)$ & $16(16 \%)$ \\
\hline Angina pectoris & $38(17 \%)$ & $22(22 \%)$ \\
\hline Myocardial infarction & $21(9 \%)$ & $14(14 \%)$ \\
\hline Hypertension & $85(38 \%)$ & $38(38 \%)$ \\
\hline \multicolumn{3}{|l|}{ Qualifying stroke } \\
\hline Cerebral infarction & $202(91 \%)$ & $91(90 \%)$ \\
\hline Intracerebral haemorrhage & $21(9 \%)$ & $9(9 \%)$ \\
\hline \multicolumn{3}{|l|}{ Motor function disorder } \\
\hline Can walk unassisted & $6(3 \%)$ & $7(8 \%)$ \\
\hline Left arm paresis & $132(59 \%)$ & $53(54 \%)$ \\
\hline Left leg paresis & $130(58 \%)$ & $57(57 \%)$ \\
\hline Right arm paresis & $91(41 \%)$ & $44(44 \%)$ \\
\hline Right leg paresis & $89(40 \%)$ & $41(41 \%)$ \\
\hline \multicolumn{3}{|l|}{ Sensory function disorder } \\
\hline Left arm & $66(30 \%)$ & $27(27 \%)$ \\
\hline Left leg & $58(26 \%)$ & $25(25 \%)$ \\
\hline Right arm & $34(15 \%)$ & $24(24 \%)$ \\
\hline Right leg & $32(14 \%)$ & $19(19 \%)$ \\
\hline \multicolumn{3}{|l|}{ Language function } \\
\hline Motor aphasia & $30(14 \%)$ & $11(11 \%)$ \\
\hline Sensory aphasia & $6(3 \%)$ & $2(2 \%)$ \\
\hline Combined aphasia & $10(5 \%)$ & $5(5 \%)$ \\
\hline Hemianopia & $64(29 \%)$ & $12(12 \%)$ \\
\hline Apraxia & 30 (14\%) & $12(12 \%)$ \\
\hline Neglect & $73(33 \%)$ & $10(10 \%)$ \\
\hline \multicolumn{3}{|l|}{ Trunk ataxia } \\
\hline Severe & $59(27 \%)$ & $10(10 \%)$ \\
\hline Moderate & $74(33 \%)$ & $33(33 \%)$ \\
\hline None & $90(40 \%)$ & $58(57 \%)$ \\
\hline \multicolumn{3}{|l|}{ Health status } \\
\hline GCS & 14 (14 to 14$)$ & 14 (14 to 14$)$ \\
\hline MRS & $4(4$ to 5$)$ & $4(4$ to 5$)$ \\
\hline $\mathrm{MBI}$ & $6(3$ to 10$)$ & $7(4$ to 10$)$ \\
\hline AbMMSE & $10(8$ to 11$)$ & $9(8$ to 11$)$ \\
\hline CES-D & $17(14$ to 20$)$ & $16(13$ to 20$)$ \\
\hline
\end{tabular}

Values are $\mathrm{n}(\%)$, mean (SD), or median (interquartile range). AbMMSE, abbreviated mini-mental state examination 0-12 (low score $=$ low level of cognitive function $)^{21} ;$ CES-D, Center of

Epidemiological Studies depression scale (score $>16=$ depression) ${ }^{22}$; GCS, Glasgow coma scale ${ }^{23} ; \mathrm{MBI}$, modified Barthel index scale 0-20 (low score=low level of physical function) ${ }^{24}$; MRS, modified Rankin scale 0-6 $(10=\text { no handicap })^{20}$; NDT, neurodevelopmental treatment.

that were recorded are represented in table 1. Neurological examination was carried out on admission. Depression was evaluated using the Center of Epidemiological Studies depression scale (CES-D). ${ }^{22}$

\section{Treatment conditions}

The six NDT wards had already implemented the NDT method for stroke patients before participation in the study. During the first phase of the study an intervention check was conducted to evaluate the nurses' compliance with the NDT guidelines. These guidelines include stimulation of bilateral limb function, suppression of abnormal patterns of movement, and promotion of advanced postural reactions.
This approach was used during each contact with the patient. At the NDT wards an NDT manual could be used for reference purposes. ${ }^{25}$ Nurses $(\mathrm{n}=144)$ were found to have adequate competence in NDT nursing, as the mean score for each of the six neurological wards was above the preset limit of $60 \%$. The interventions by the physiotherapists in the 12 hospitals $(\mathrm{n}=38)$ was measured by a questionnaire on their NDT education, using a case vignette. Physiotherapists in NDT hospitals had sufficient NDT competence, while in the nonNDT hospitals they did not. The other six wards used conventional (that is, non-NDT) nursing and the physiotherapists did not use NDT. We assessed the general level of quality of nursing care not related to the NDT approach on the participating wards to control for possible differences between the groups. The instrument to measure quality of nursing care had 25 items and was based on two existing Dutch instruments. It proved to have good content validity and inter-rater reliability. No difference was found in the general level of quality of nursing care $(p=0.49)$, indicating good comparability between the two groups.

The intervention continued after discharge, as confirmed by a survey among the nurses and physiotherapists providing postdischarge treatment. The patients in the NDT group continued to receive NDT treatment in the nursing and community homes and rehabilitation centres after discharge, while those in the non-NDT group did not receive this treatment.

\section{Outcome measures and instruments}

The primary outcome was "poor outcome" at 12 months, defined as a modified Barthel index of less than 12 or death. The Barthel index represents a patient's ability to carry out the everyday activities (bladder and bowel control, toilet use, dressing, feeding, walking, personal toilet, transfer activities, bathing, and stair climbing). ${ }^{24}$ This outcome was also assessed at discharge and after six months. After six and 12 months, QoL was measured with the stroke adapted 30 item version of the

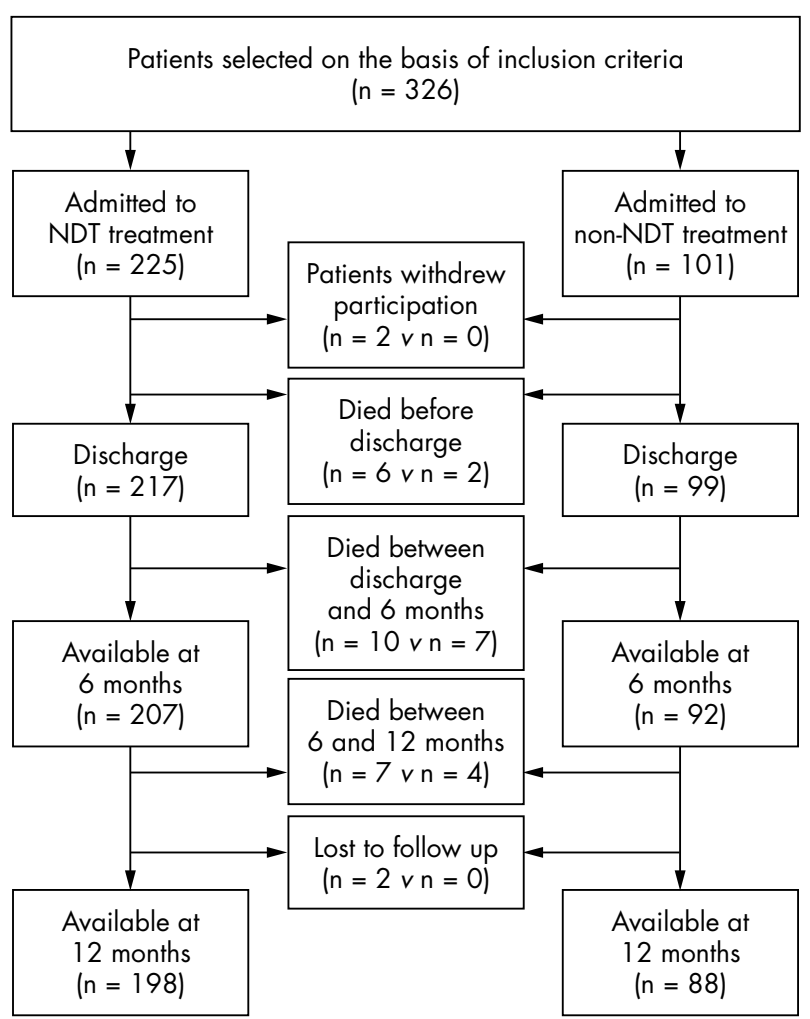

Figure 1 Flow chart of the patients included in the study. 
Table 2 Management of patients and treatment given during hospital admission

\begin{tabular}{|c|c|c|}
\hline Variable & $\begin{array}{l}\text { NDT treatment } \\
(n=217)\end{array}$ & $\begin{array}{l}\text { Non-NDT treatment } \\
(\mathrm{n}=99)\end{array}$ \\
\hline $\begin{array}{l}\text { Length of hospital stay (d) } \\
\text { Physical therapy (times/week) } \\
\text { Occupational therapy } \\
\text { (times/week) } \\
\text { Speech language therapy } \\
\text { (times/week) } \\
\text { Discharged from hospital to: } \\
\text { Home } \\
\text { Nursing home } \\
\text { Rehabilitation centre } \\
\text { Other }\end{array}$ & $\begin{array}{l}26(17 \text { to } 40) \\
5(2) \\
2(2) \\
1(2)\end{array}$ & $\begin{array}{l}25(16 \text { to } 34) \\
4(2) \\
1(2) \\
1(1)\end{array}$ \\
\hline
\end{tabular}

Values are mean (SD), $\mathrm{n}(\%)$, or median (interquartile range).

NDT, neurodevelopmental treatment.

sickness impact profile (SA-SIP30), of which only overall results are reported here. ${ }^{26}$ QoL was also measured with a visual analogue scale (VAS) asking patients to respond to the question "How do you perceive your quality of life?" and to rate their perception of QoL by putting a mark on a $100 \mathrm{~mm}$ line. ${ }^{27}$

\section{Data collection}

In the participating hospitals, specially trained research assistants conducted the baseline and discharge assessments. At follow up, postal questionnaires were sent to the patients. Uniform study procedures were followed in all participating hospitals. Before the data collection the inter-rater reliability between the first author and the research assistants was measured on 12 patients and showed excellent agreement $(\kappa>0.75)$.

\section{Statistical analysis}

We aimed to recruit 200 patients in each treatment group. These numbers would suffice to detect an absolute difference of $14 \%$ in poor outcome at 12 months (Barthel index $<12$ ) with sufficient statistical precision $(\alpha=0.05, \beta=0.20)$.

The proportion of patients with poor outcome at 12 months was compared between the study groups. The result was expressed as an odds ratio with corresponding 95\% confidence intervals. Baseline incomparabilities between the study groups were taken into account in multivariate logistic regression analysis, resulting in adjusted odds ratios. Adjusted mean differences of the QoL measures between the two study groups were calculated by linear regression.

\section{RESULTS}

\section{Patients}

In all, 326 patients were included in the study (fig 1). Two patients in the NDT group withdrew from participation during hospital stay and therefore the analysis was based on

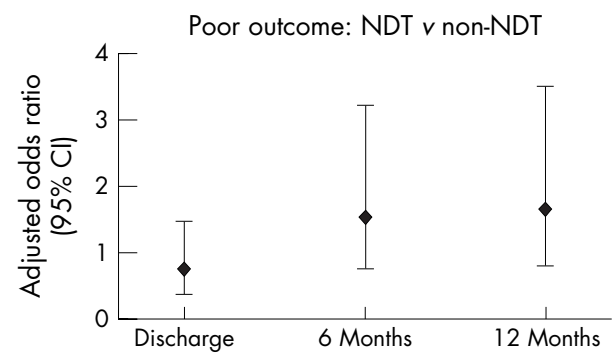

Figure 2 Comparative effects of the neurodevelopmental treatment (NDT) approach on the functional status (Barthel index) adjusted for baseline differences with the multivariate logistic regression analysis. the data from 324 patients, 223 in the NDT group and 101 in the non-NDT group. Baseline characteristics are summarised in table 1 .

The length of stay in the hospital was 26 days for the NDT group and 25 days for the non-NDT group. The patients in the NDT group received slightly more physiotherapy (five times a week) and occupational therapy (two times a week) than the non-NDT group (physiotherapy four times a week and occupational therapy once a week) (table 2 ). Thirty four per cent of the non-NDT patients and 30\% of the NDT patients were discharged home. Mortality at 12 months was $11 \%$ in the NDT group and $13 \%$ in the non-NDT group. At 12 months, $84 \%$ of the surviving patients in the NDT group and $85 \%$ in the non-NDT group were living at home.

\section{Effects of the therapeutic intervention}

At 12 months, 59 patients in the NDT group (27\%) had a poor outcome, as did $24(24 \%)$ in the non-NDT group (table 3$)$. The corresponding crude odds ratio was 1.2 (95\% confidence interval (CI), 0.7 to 2.0). After simultaneous adjustment for the seven variables that changed the crude odds ratio by more than $5 \%$ in single variable adjustment (age, living situation, education, modified Rankin scale, Barthel index, MMSE, and CES-D), the odds ratio was 1.7 (0.8 to 3.5). Data on outcome at discharge and after six and 12 months are presented in table 3 and fig 2.

Table 4 gives data on SA-SIP30 and VAS for each of the treatment groups at six and 12 months. At neither time point was there a differences in these measures, or if imbalances between the treatment groups at baseline were taken into account.

\section{DISCUSSION}

Our study showed no effect of NDT during hospital care with respect to outcome assessed at six and 12 months after stroke onset. We were also unable to find any beneficial effects on quality of life measures at any time after stroke.

NDT nursing is quite different from conventional nursing and in order to be capable of using NDT nursing, nurses needed to have specialised NDT education and training. To verify compliance with the NDT approach an intervention check was conducted measuring the nurses' and the physiotherapists' competence in providing the NDT treatment. In the hospitals not using NDT, the nurses employed conventional nursing and the physiotherapists did not use NDT, as confirmed by the intervention check. ${ }^{28} 29$ The quality of general nursing care on the participating wards was found to be similar in the two groups. ${ }^{30}$ Thus we believe that we really were evaluating the potential treatment effect of the NDT approach. Although the NDT group received slightly more physical therapy during the hospital stay, this did not result in better outcome on any of the variables measured. The length of hospital stay was similar for the two groups.

A randomised clinical trial would have been ideal in the evaluation of the efficacy of the NDT approach. This, however, was not feasible, because randomisation at the patient level was not possible: a ward either uses the NDT approach or it does not. Because, random reallocation of patients after admission was considered impossible, we used a pragmatic approach in which we compared patients admitted to wards that did or did not employ the NDT approach. A major disadvantage with this observational approach is non-comparability of prognosis between treatment groups. For this reason we collected extensive data on determinants of poor outcome in both treatment groups and adjusted our effect estimates for differences between the groups. Hence we consider our effect estimates to be valid.

Another limitation of the study was the unequal distribution of patients between the two study groups. The lack of hospitals 
Table 3 Functional outcome at discharge, six, and 12 months after stroke

\begin{tabular}{|c|c|c|c|c|}
\hline \multirow[b]{2}{*}{ Functional outcome } & \multicolumn{4}{|l|}{ Treatment } \\
\hline & $\mathrm{NDT}^{*}(n=223)$ & Non-NDT ${ }^{*}(n=101)$ & OR (Cl), crude & OR (CI), adjusted \\
\hline \multicolumn{5}{|l|}{$\begin{array}{l}12 \text { months (primary } \\
\text { outcome) }\end{array}$} \\
\hline $\begin{array}{l}\text { Poor outcome } \\
\text { Barthel index }\end{array}$ & $\begin{array}{l}59(27 \%) \\
18(13 \text { to } 17)\end{array}$ & $\begin{array}{l}24(24 \%) \\
17(14 \text { to } 20)\end{array}$ & $1.2(0.7$ to 2.0$)$ & 1.7 (0.8 to 3.5$)$ \\
\hline \multicolumn{5}{|l|}{ Discharge } \\
\hline $\begin{array}{l}\text { Poor outcome } \\
\text { Barthel index }\end{array}$ & $\begin{array}{l}97(44 \%) \\
13 \text { (8 to 17) }\end{array}$ & $\begin{array}{l}45(45 \%) \\
12(9 \text { to } 18)\end{array}$ & 1.0 (0.6 to 1.5$)$ & $0.8(0.4$ to 1.5$)$ \\
\hline \multicolumn{5}{|l|}{ Six months } \\
\hline Poor outcome & $63(29 \%)$ & $25(25 \%)$ & & \\
\hline Barthel index & 18 (12 to 20$)$ & 18 (14 to 20$)$ & $1.2(0.7$ to 2.0$)$ & $1.6(0.8$ to 3.2$)$ \\
\hline
\end{tabular}

not using NDT hampered patient inclusion in the conventional group. However, despite this limitation we believe that our results for the primary outcome at 12 months are hardly compatible with an important beneficial effect of NDT.

Some critics may consider that the instruments used in our study were not sensitive enough to detect the effects of NDT treatment. However, we assessed both functional status and quality of the life with established measures, so we feel to have covered two domains that are of major relevance for the patient. Previous studies have already focused on several other outcome measures such as walking ability, ${ }^{8-10}$ motor performance, ${ }^{811}$ muscle strength, ${ }^{8}{ }^{12}$ upper extremity function, ${ }^{13}$ and depression, ${ }^{10}$ but these were also unaffected by the NDT approach.

Information on the Barthel index or vital status was obtained by questionnaire, filled out by the patient or a partner. We doubt whether, at the time of completing the questionnaires, the patients were aware of the purpose of the research, as previous studies have shown that this type of information does not leave a lasting impression. ${ }^{31}$ Hence, we consider the assessment of outcome to be largely unbiased.

No previous study has measured the effects of the NDT approach on functional outcome in the course of a year after a stroke. The small trend to a positive effect on functional status found at discharge, which was also found in an earlier study, ${ }^{14}$ had entirely disappeared by six months. The limited early effect may be attributable to an adequate NDT contrast between the treatment groups during the hospital stay. Even though we did not carry out a formal intervention check on NDT use after discharge, a survey of the rehabilitation approaches used in this period indicated that there were no major changes in the treatment given to the groups after the discharge from hospital. Obviously, for ethical reasons it was not possible to use a group with no rehabilitation as the contrasting limb of the study.

The effects of the NDT approach on quality of life have not been investigated before. As was the case for functional outcome, we found no difference between the treatment groups. In both groups a large proportion of the patients experienced a considerable deterioration in quality of life. One year after the stroke the NDT group scored 35 on the SASIP30 (equivalent to a 136 item SIP of 24) and the non-NDT group scored 39 (equivalent to a 136 item SIP of 26), which is practically the same outcome as at six months. This is similar to a previously reported SIP-136 score of 23 at six months ${ }^{32}$ and 24 at three years after the stroke. ${ }^{33}$ Although most patients reached almost full recovery in terms of mobility and activities of daily living, as indicated by the Barthel index at six and 12 months (median values of 17 to 18 ), they estimated their quality of life as low. This is probably because of a ceiling effect of the Barthel index, as studies have shown that deterioration in the quality of life is linked to an increase in disability in the activities of daily living. ${ }^{27}$

Recovery after stroke may best be stimulated by the patient practising motor tasks under similar conditions of strength, speed, and accuracy as in real life, and with similar cognitive demands. $^{34}$ One wonders to what extent nurses and therapists are actually training patients in these basic aspects of rehabilitation. How much time do nurses spend on walking with patients and on assisting them with therapeutic movements? In light of the fact that stroke patients on rehabilitation units spend only $13 \%$ of their time on treatment and up to $40 \%$ of the most active part of the day in passive pursuits such as sitting unoccupied, ${ }^{35}$ nurses need to reconsider how they are fulfilling their role when caring for such patients. Also, little attention is given to the basic

Table 4 Quality of life at six and 12 months after stroke

\begin{tabular}{llll}
\hline Quality of life & NDT treatment & & Non-NDT treatment \\
& Six months & Adjusted difference $(95 \%$ Cl)t \\
SA-SIP30 & $n=206$ & $n=93$ & \\
VAS & $40(28$ to 56$)$ & $38(25$ to 61$)$ & $0.2(-4.7$ to 5.0$)$ \\
& $49(30$ to 64$)$ & $50(32$ to 69$)$ & $0.8(-5.3$ to 7.0$)$ \\
12 months & $n=198$ & $n=85$ & \\
SA-SIP30 & $35(23$ to 49$)$ & $39(20$ to 52$)$ & $1.6(-6.2$ to 2.9$)$ \\
VAS & $50(30$ to 67$)$ & $50(36$ to 70$)$ & $2.7(-9.1$ to 3.6$)$ \\
\hline
\end{tabular}

*Values are median (interquartile range).

†Adjusted for age, living situation, education, modified Rankin scale, Barthel index, MMSE, and CES-D.

CES-D, Center of Epidemiological Studies depression scale; CI, confidence interval; MMSE, mini-mental state examination; NDT, neurodevelopmental treatment; OR, odds ratio. 
aspects of rehabilitation of stroke patients in nursing education. ${ }^{36}$ This is strange in the light of the fact that care and treatment of patients with stroke poses a great burden on the health care system.[37] Surely more attention should be paid to these issues in the future.

On the basis of the findings of this and previous studies, there seems to be little place for the NDT approach in the hospital treatment of patients with stroke. Efforts should be made to develop an integrated rehabilitation approach not only focusing on physical functioning of the patient, but also on psychosocial, perceptual, cognitive, and behavioural experiences. The effects of such new approaches should be properly assessed before they are implemented at a large scale. Only in this way may it be possible to improve the functional outcome and overall quality of life of patients with stroke.

\section{MEMBERS OF THE DUTCH NDT STUDY GROUP}

Executive committee: Thóra B Hafsteinsdóttir, Ale Algra, L Jaap Kappelle, Maria H F Grypdonck.

Participating centres and nurses: BovenIJ Ziekenhuis Amsterdam $(\mathrm{n}=38)$ : Emmy Berends, Els Jansen, Maureen Koster, Yvette Schotsman, Ada Wimmers; Canissius Wilhelmina Ziekenhuis Nijmegen $(\mathrm{n}=21)$ : Roel Dousi; Elizabeth Ziekenhuis Tilburg $(\mathrm{n}=40)$ : Marcel Boonen, Cindy Franssen, Wim van Veenendaal; Gemini Ziekenhuis Den Helder $(\mathrm{n}=16)$ : Hanneke Kuiper, Petra Schop; Kennemer Gasthuis Haarlem $(\mathrm{n}=7)$ : Marion Baars, Anita Sanders; Leyenburg Ziekenhuis Den Haag $(\mathrm{n}=4)$ : Yvonne Drabbe, Karin Gerbrands; Martini Ziekenhuis Groningen $(\mathrm{n}=44)$ : Attie Nauta, Karin Strijker, Jantje Veen; Medisch Centrum Vrije Universiteit $(\mathrm{n}=14)$ : Marian Baartscheer, Janine Boer, Lies Braam, Kees Goverde, Ans Kupper-Steenstra, Lies van der Weide; Spaarne Ziekenhuis Haarlem $(\mathrm{n}=25)$ : Annemiek Koppenhol, Petra Romijn; Universitair Medisch Centrum Nijmegen $(\mathrm{n}=28)$ : Paul van Keeken, Henk Muessen, Theo de Waal, Jose van Welie; Universitair Medisch Centrum Utrecht $(\mathrm{n}=67)$ : Caroline Ackermans, Florus Waszink; Zaans Medisch Centrum Zaandam $(\mathrm{n}=22)$ : Carien Biersteker, Anneke Mak, Els Scheepbouwer, Geert Schilstra.

\section{ACKNOWLEDGEMENTS}

We thank C Kruitwagen, Professor C Frederiks, and Professor T van Achterberg for their advice. The comments of Prof J van Gijn on the manuscript are greatly appreciated. The authors are indebted to the patients for their participation in the study, the carers for their assistance, and the nurses and physiotherapists working in the hospitals, nursing homes and rehabilitation centres where the patients stayed during the study. This research project was supported by a grant from the University Medical Centre Utrecht and the Janivo Fund, Zeist, Netherlands.

\section{Authors' affiliations}

T B Hafsteinsdóttir, Rudolph Magnus Institute of Neurosciences, Department of Neurology, and Julius Centre for Health Sciences and Primary Care, Department of Nursing Sciences, University Medical Centre Utrecht, Utrecht, Netherlands

A Algra, Julius Centre for Health Sciences and Primary Care, Department of Clinical Epidemiology, and Rudolph Magnus Institute of Neurosciences, Department of Neurology, University Medical Centre Utrecht

L J Kappelle, Rudolph Magnus Institute of Neurosciences, Department of Neurology, University Medical Centre Utrecht

M H F Grypdonck, Julius Centre for Health Sciences and Primary Care, Department of Nursing Sciences, University Medical Centre Utrecht

Competing interests: none declared

\section{REFERENCES}

1 Bobath B. Adult hemiplegia: evaluation and treatment. Oxford: Butterworth Heinemann, 1990.
2 Hafsteinsdóttir TB. Neurodevelopmental treatment: application to nursing and effects on the hemiplegic stroke patient. J Neurosci Nurs 1996;28:36-47.

3 Davidson I, Waters K. Physiotherapists working with stroke patients: a national survey. Physiotherapy 2000;86:69-80.

4 Nudo RJ, Friel KM. Cortical plasticity after stroke: implications for rehabilitation. Rev Neurol Paris 1999;155:713-17.

5 Lee RG, Van Donkerlaar P. Mechanisms underlying functional recovery following stroke. Can J Neurol Sci 1995;22:257-63.

6 Davies P. Right in the middle. Selective trunk activity in the treatment of adult hemiplegia. Berlin: Springer, 1990.

7 Goodgold-Edwards SA. Principles for guiding action during motor learning: a critical evaluation of neurodevelopmental treatment. Phys Ther Pract 1993;2:30-9

8 Dickstein R, Hocherman S, Pillar T, et al. Stroke rehabilitation. Three exercise therapy approaches. Phys Ther 1986:66:1233-8.

9 Mulder T, Hulstijn W, van der MJ. EMG feedback and the restoration of motor control. A controlled group study of 12 hemiparetic patients. Am J Phys Med 1986;65:173-88

10 Wagenaar RC, Meijer OG, van Wieringen PC, et al. The functional recovery of stroke: A comparison between neuro-developmental treatment and the Brunnstrom method. Scand J Rehabil Med 1990;22:1-8.

11 Langhammer B, Stanghelle JK. Bobath or Motor Relearning Programme? A comparison of two different approaches of physiotherapy in stroke rehabilitation: a randomized controlled study, Clin Rehabil 2000;14:1-9.

12 Logigian MK, Samuels MA, Falconer JA, et al. Clinical exercise trial for stroke patients. Arch Phys Med Rehabil 1983;64:364-7.

13 Basmajian JV, Gowland CA, Finlayson MA, et al. Stroke treatment: comparison of integrated behavioral-physical therapy vs traditional physical therapy programs. Arch Phys Med Rehabil 1987;68:267-72.

14 Lewis NA. Functional gains in CVA patients: a nursing approach. Rehabil Nurs 1986;11:25-7.

15 Lord JP, Hall K. Neuromuscular reeducation versus traditional programs for stroke rehabilitation. Arch Phys Med Rehabil 1986;67:88-91.

16 World Health Organisation. International classification of functioning, disability and health (ICF). Geneva: WHO, 2001

17 Pollock A, Baer G, Pomeroy V, et al. Physiotherapy treatment approaches for the recovery of postural control and lower limb function following stroke (Cochrane Review). In: The Cochrane Library, issue 3, 2004. Chichester: John Wiley and Sons.

18 WHO. Recommendations on stroke prevention, diagnosis, and therapy: report of the WHO Task Force on Stroke and other Cerebrovascular disorders. Stroke 1989;20:1407-31.

19 Teasdale TW, Christensen AL, Pinner EM. Psychosocial rehabilitation of cranial trauma and stroke patients. Brain Injury 1993;7:535-42.

20 Bamford JL, Sandercock PAG, Warlow CP, et al. Interobserver agreement for the assessment of handicap in stroke patients. Stroke 1989;20:828.

21 Kempen GIJM, Brilman El, Ormel J. De Mini-Mental State Examination: Normeringsgegevens en een vergelijkiing van een 12-en 20 -items versie in een steekproef ouderen vit de bevolking. Tijdschr Gerontol Geriatr 1995;26:163-72. [In Dutch.]

22 Radloff LS, Teri L. Use of the Center for Epidemiological Studies depression scale with older adults. In: Clinical gerontology. New York: The Hawthorne Press, 1986.

23 Teasdale G, Murray G, Parker L, et al. Adding up the Glasgow coma scale. Acta Neurochi (Wien) 1979;28:13-16.

24 Mahoney FI, Barthel DW. Functional evaluation: the Barthel Index. Maryland Med J 1965;14:61-5.

25 van Keeken PRC, Kaemingk M. Handboek Neurodevelopmental Treatment: een praktische leiddraad voor verpleegkundigen en paramedici. Maarssen: Elsevier/Tiidstroom, 1999. [In Dutch.]

26 van Straten A, de Haan RJ, Limburg M, et al. A stroke-adapted 30-item version of the Sickness Impact Profile to assess quality of life (SA-SIP30). Stroke 1997;28:2155-61.

27 Ahlsio B, Britton M, Murray V, et al. Disablement and quality of life after stroke. Stroke 1984;15:886-90.

28 Hafsteinsdóttir TB, Grypdonck M. NDT-nursing competence measured with nurses in the rehabilitation of stroke patients. In: Neurodevelopmental treatment in the early stage of stroke. Utrecht: University of Utrecht, 2003. [Doctoral thesis.]

29 Hafsteinsdóttir TB, van Meeteren N, Grypdonck M. Is neurodevelopmental treatment used by physiotherapists in the care of stroke patients? In: Neurodevelopmental treatment in the early stage of stroke. Utrecht: University of Utrecht, 2003. [Doctoral thesis.]

30 Hafsteinsdóttir TB, Kruitwagen C, Strijker K, et al. Implementation of NDTnursing: Is NDT implemented on better wards? In: Neurodevelopmental treatment in the early stage of stroke. Utrecht: University of Utrecht, 2003. [Doctoral thesis.]

31 Schats R, Brilstra EH, Rinkel GJ, et al. Informed consent in trials or neurological emergencies: the example of subarachnoid haemorrhage. J Neurol Neurosurg Psychiatry 2003;74:988-91.

32 de Haan RJ, Limburg M, van der Meulen JH, et al. Quality of life after stroke. Impact of stroke type and lesion location. Stroke 1995;26:402-8.

33 Nydevik I, Hulter AK. Sickness impact after stroke. Scand J Prim Health Care 1992;10:284-9.

34 Carr JH, Shepherd R. Neurological rehabilitation: optimising motor performance. Oxford: Butterworth Heinemann, 2000.

35 Tinson DJ. How stroke patients spend their days. An observational study of the treatment regime offered to patients in hospital with movement disorders following stroke. Int Disabil Stud 1989;11:45-9.

36 Gibbon B. Implications for nurses in approaches to the management of stroke rehabilitation: a review of the literature. Int J Nurs Stud 1993;30:133-41. 